\title{
Sales of Consumer Chemicals in Zero-packaging Stores - a Challenge for Small and Medium-sized Chemical Companies
}

\author{
Lenka BRANSKA ${ }^{1 *}$, Michal PATAK ${ }^{1}$; Katerina HROMADNIKOVA ${ }^{1}$ and Zuzana \\ PECINOVA $^{1}$ \\ ${ }^{1}$ University of Pardubice, Pardubice, Czech Republic; lenka.branska@upce.cz; michal.patak@upce.cz; \\ katerina.hromadnikova@student.upce.cz; zuzana.pecinova@upce.cz \\ *Correspondence: lenka.branska@upce.cz
}

\begin{abstract}
One of the innovations in the area of increasing the sustainability of packaging may be the introduction of zero-packaging sales. The paper deals with the advantages and disadvantages of zero-packaging sales, in relation to consumer chemicals. It presents the results of primary quantitative research carried out with 100 final consumers through electronic surveys using a structured questionnaire. Content analysis and multiple response analysis were used to identify the most significant advantages and disadvantages of purchasing consumer chemicals in zero-packaging stores. The biggest advantages are the reduction of waste from packaging materials, being able to buy the exact quantity required, and environmental protection. The biggest disadvantages include the insufficient expansion of the stores, the necessity to carry their own containers and the higher price of products sold. The advantage of "selling quality products" and the disadvantages of "uncertainty in terms of composition and quality" and "hard-to-observe hygiene requirements" are perceived differently depending on whether or not customers actually buy consumer chemicals in zeropackaging stores. The conclusions are important in terms of the possibility of creating a competitive advantage of small and medium-sized companies.
\end{abstract}

Keywords: sustainable supply chain; retail; zero-packaging; chemical product

JEL Classification: Q01; M31; L81

\section{Introduction}

Population growth and rate of consumption increase the volume of packaging used throughout the supply chain. A larger volume of packaging is needed not only in all stages of the gradual creation of the final product, but also for the final products (Meherishi et al., 2019). The need for packaging material is enormous indeed, with 100,000 products packed in the world every second (Vörös, 2019).

As a result, the demands on packaging and the constant increase thereof pose a challenge for companies and academia to find solutions ensuring packaging sustainability. The idea is becoming prevalent that the design of sustainable packaging should include both the design of technical parameters and logistical and environmental parameters (Dominic et al., 2015). Packaging materials should be made from renewable sources, recyclable, composable. They 
should also be cheap and with such physical and chemical properties as to allow easy adaptation to different uses (Farooque et al., 2019).

Companies are currently looking for a way to more environmentally friendly packaging. One of their main drivers is the effort to achieve economic benefits as a result of gaining a more valuable product or new customers (Civancik-Uslu et al., 2019). However, environmentally oriented packaging innovations are not implemented in the same way in all industries. According to Meherishi et al. (2019), these innovations are mainly introduced by food companies, however, companies in the chemical and pharmaceutical industries as well as retail businesses (especially electronic) have also implemented sustainable packaging.

In order to increase the sustainability of packaging, chemical and pharmaceutical companies usually seek to reduce the volume of plastics used in connection with packaging. For example, Dow Chemicals Company has begun to develop sustainable solutions for all of its plastic-packed products. It endeavours to use less material, with less weight, creating less waste (Dow, 2020). Another option for innovations in order to reduce plastic is to use new materials or change the size or type. As for the size of the package, it is appropriate to increase it if customers buy more than one package at a time, while reducing it is appropriate if the product is often not consumed before the expiration date (Gustavo et al., 2018).

However, the above-mentioned options for increasing sustainability do not represent the only directions of implemented packaging innovations in general, not even in companies in the chemical and pharmaceutical industries. Other possibilities are also mentioned in the literature, in particular 'reuse/recycle/remanufacture/return of packaging' (Meherishi et al., 2019).

A fundamentally different way to increase the sustainability of packaging is the introduction of zero-packaging sales. From the point of view of traditional retail sales, this is a relatively new variant, however, in the last 10 years, a large number of these stores have been opened worldwide and in the European context (Istas, 2019; Beitzen-Heineke et al. 2017). For example, the first zero-packaging store in Belgium was opened in 2014 and it is currently estimated that there are 45 such stores. In the Czech Republic, the first projects of this kind appeared at about the same time. Consumer chemicals belong to the assortment sold in these stores as standard.

Zero-packaging stores are based on the concept of zero-packaging. This means that consumers bring their own packaging to these stores, which they fill and pay according to the weight of the product purchased. Zero-packaging stores sell fruit and vegetables, dry products (wheat, pasta, rice, lentils, etc.) and products in liquid or semi-liquid form, such as milk, yoghurt or jam. From the point of view of consumer chemicals, cleaning products and products for personal hygiene (e.g. soap and shampoo) are offered. Zero-packaging sale mainly removes primary packaging, secondary and tertiary packaging cannot be removed completely. However, secondary and tertiary packaging is usually replenished by the supplier or the empty ones are replaced with full ones. If the store cooperates with a supplier who does not use the packaging repeatedly, it often endeavours to use it internally or find another use for it and thus extend the period of its use (Beitzen-Heineke et al., 2017). 
Zero-packaging stores represent an opportunity to radically reduce the volume of packaging, however, in contrast to traditional sales, they are far from being used as much, neither when buying food nor consumer chemicals. The main reason is probably mainly related to the customer. According to Ma et al. (2020) customer is the best driver and the second most common barrier to packaging innovation in the FMCG sector. Zero-packaging stores will be expanded if their operation is possible in terms of technical and organizational barriers and if customers use them. They will do so if their perception of advantages exceeds the perception of disadvantages. So far, only a few researches on the advantages and disadvantages of purchasing in zero-packaging stores have been carried out, none of them focused on the purchase of consumer chemicals.

Previous research in this area shows that the main reasons for customers to do the shopping in zero-packaging stores are not only waste elimination, reducing the environmental impact (Price, Waterhouse \& Co, 2015; Salkova \& Regnerova, 2020) and quality of products sold, but also reducing the need for waste collection, non-collection of things and the use of reusable packaging instead of disposable packaging (Salkova \& Regnerova, 2020). According to previous research, the main disadvantages are: limited range of products, higher demands on the shopping (especially the necessity to prepare for the shopping) (Beitzen-Heineke et al., 2017; Salkova \& Regnerova, 2020), unavailability and a small number of stores (Salkova \& Regnerova, 2020), greater time expenditure of the purchase and all-day transfer of packaging, if the shopping is done only after leaving work) (Beitzen-Heineke et al., 2017).

The literature also deals with the risks associated with shopping in zero-packaging stores. The identified risks mainly include the threat of contamination of purchased products due to poorly cleaned packaging brought by the customer (Beitzen-Heineke et al. 2017); LEAD Innovation Blog, 2020), safety of transport, durability or labelling (LEAD Innovation Blog, 2020). These problems are more pronounced in cosmetic, pharmaceutical and hygienic products (LEAD Innovation Blog, 2020).

A study (Price, Waterhouse \& Co, 2015) also reveals another problem that may affect the development of zero-packaging stores. Zero-packaging stores are positively perceived by most consumers, but only a minority would be willing to pay higher prices.

Primary quantitative research has been carried out in order to be able to develop knowledge in the area of advantages and disadvantages of purchasing in zero-packaging stores, especially in connection with consumer chemicals. Its purpose was to reveal the share of consumers who purchase consumer chemicals in zero-packaging stores and the perception of the advantages and disadvantages of this method of purchase from the customer's point of view. The research has contributed to the development of theoretical knowledge in the field of zero-packaging sales, both in general and in relation to consumer chemicals. Therefore, its conclusions can be used by both academia and businesses, including those outside the chemical industry. They can be used especially by small and medium-sized companies, for which, by understanding the perceived advantages and disadvantages, zeropackaging sale can become an opportunity to gain a competitive advantage. 


\section{Methodology}

The aim of the primary research was to specify the attitudes of Czech consumers to the zero-packaging sale of consumer chemicals (for laundry, cleaning and hygiene purposes). The partial goals were intended to identify:

- the frequency of purchasing consumer chemicals in zero-packaging stores,

- willingness to recommend the purchase of consumer chemicals in zero-packaging stores,

- perceived advantages and disadvantages of purchasing consumer chemicals in zeropackaging stores and

- differences in perceived advantages and disadvantages depending on whether the consumer does the shopping in zero-packaging stores.

The research was organized as quantitative in a group of economically active inhabitants in the Czech Republic (15-64 years). Data collection was carried out using the quota selection method with quotas linked to the age and sex of the respondent, according to data from the Czech Statistical Office as at December 31, 2019 (Czech Statistical Office, 2020). Data collection took place in the period April - May 2020 via an electronic survey using a structured questionnaire, which was piloted on 10 respondents before the start of the research. The survey included 100 respondents in the required structure (see Table 1).

Table 1. Structure of respondents by sex and age

\begin{tabular}{|c|c|c|c|c|c|c|}
\hline \multirow{2}{*}{ Sex } & \multicolumn{5}{|c|}{ Age } & \\
\cline { 2 - 6 } & $\mathbf{1 5 - 2 4}$ years & $\mathbf{2 5 - 3 4}$ years & $\mathbf{3 5 - 4 4}$ years & $\mathbf{4 5 - 5 4}$ years & 55-64 years & Total \\
\hline Men & $7 \%$ & $12 \%$ & $12 \%$ & $11 \%$ & $8 \%$ & $50 \%$ \\
\hline Women & $7 \%$ & $9 \%$ & $12 \%$ & $15 \%$ & $7 \%$ & $50 \%$ \\
\hline Total & $14 \%$ & $21 \%$ & $24 \%$ & $26 \%$ & $15 \%$ & $100 \%$ \\
\hline
\end{tabular}

At the beginning of the survey, the respondents were asked about the frequency of shopping in zero-packaging stores and their willingness to recommend these stores for purchasing consumer chemicals. Subsequently, the respondents were asked to specify 3 advantages and 3 disadvantages of purchasing in zero-packaging stores. At the end of the survey, selected classification features of the respondents (gender, age, education and income) were identified.

The obtained data were processed by content analysis of advantages and disadvantages, resulting in the identification of 8 categories of advantages and 9 categories of disadvantages (advantages or disadvantages with a frequency of less than 5\% were included in the category "Other"). Subsequent statistical analysis focused on comparing the importance of advantages and disadvantages in zero-packaging stores using frequency analysis and multiple response analysis. Statistical analysis identified main advantages and disadvantages from the perspective of all respondents and the differences between respondents who do the shopping in zero-packaging stores and those who do not. The statistical significance of these differences was verified by chi-square test (with continuity correction) at the $5 \%$ level of significance. 


\section{Results of the Primary Research}

The primary research helped to reveal a number of interesting facts concerning the purchase of consumer chemicals in zero-packaging stores.

\subsection{Frequency of Purchasing Consumer Chemicals in Zero-packaging Stores}

The research has shown that a relatively small number of respondents do the shopping in zero-packaging stores. Most respondents (70\%) do not shop in a zero-packaging store at all (see Figure 1).

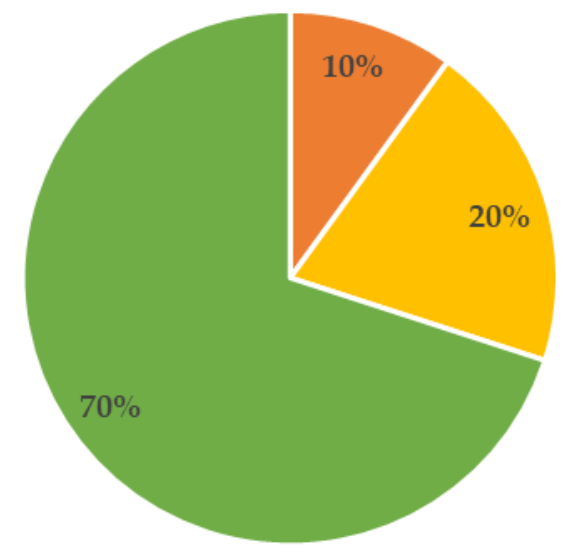

- do the shopping at least once a month

= do the shopping less often

- do not the shopping

Figure 1. Frequency of shopping in zero-packaging stores

Interestingly, however, virtually all respondents (29 out of 30) who buy consumer chemicals in zero-packaging stores also recommend this kind of shopping.

\subsection{Advantages of Purchasing Consumer Chemicals in Zero-packaging Stores}

The primary research made it possible to identify the perceived advantages of purchasing consumer chemicals in zero-packaging stores. The most frequently mentioned advantage is the reduction of waste from packaging materials (this advantage was mentioned by more than half of all respondents). Other often-mentioned advantages were being able to buy the exact quantity required and environmental protection. More than a third of respondents mentioned these three advantages (see Figure 2).

The sale of quality products at lower prices and the possibility of reusing your own packaging can be considered to be the minor advantages of purchasing consumer chemicals in zero-packaging stores. The 'Other' category covers a wide portfolio of advantages, such as personal contact with the seller, the freshness of the goods sold, a good feeling from the purchase and purchase of products mainly from local producers. 


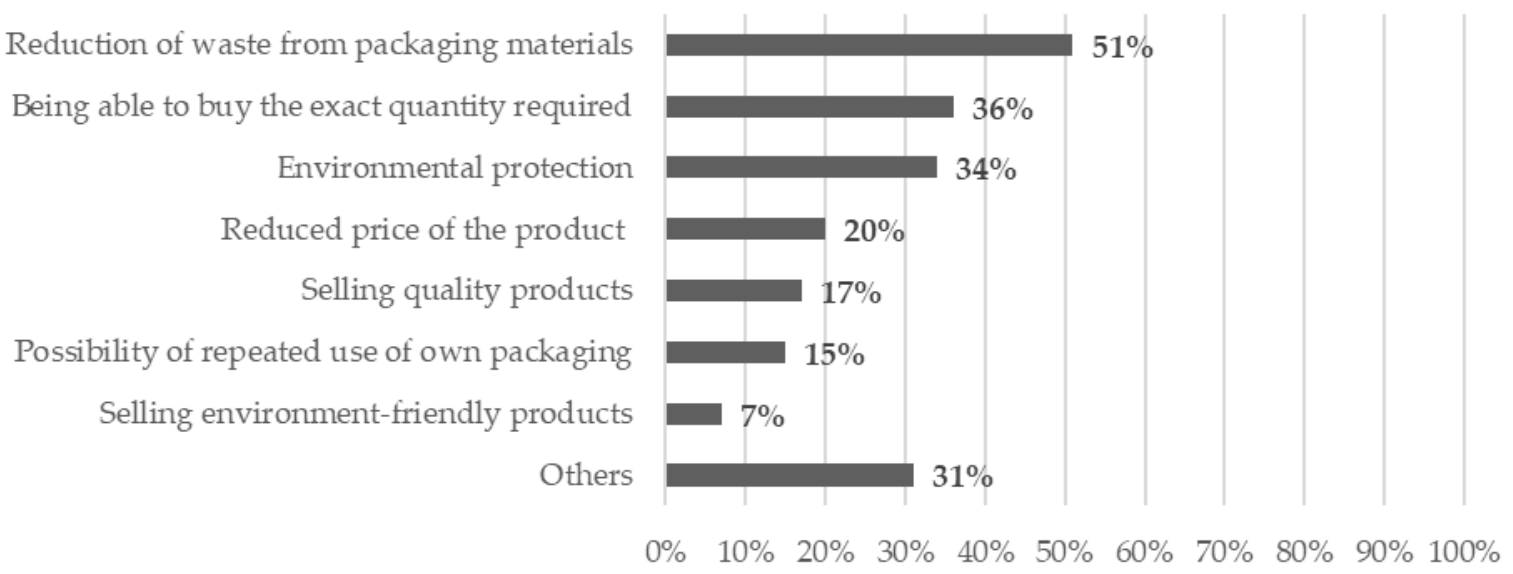

Figure 2. Advantages of shopping in zero-packaging stores

It was interesting to examine whether opinions differ on the advantages of doing the shopping in zero-packaging stores depending on whether respondents actually do the shopping in zero-packaging stores (see Table 2).

Table 2. Differences in views on the advantages of shopping in zero-packaging stores depending on whether the purchases are actually made

\begin{tabular}{|c|c|c|c|c|}
\hline \multirow{2}{*}{ Advantage } & \multicolumn{2}{|c|}{ Percent of Customers } & \multicolumn{2}{c|}{ Chi-square Test } \\
\cline { 2 - 5 } & $\begin{array}{c}\text { Regular } \\
\text { Customers }\end{array}$ & $\begin{array}{c}\text { Customers of zero- } \\
\text { packaging stores }\end{array}$ & Chi-square & P-value \\
\hline Possibility of repeated use of own packaging & $13 \%$ & $20 \%$ & 0.373 & 0.541 \\
\hline Selling quality products & $10 \%$ & $33 \%$ & 6.534 & 0.011 \\
\hline Reduction of waste from packaging materials & $53 \%$ & $47 \%$ & 0.122 & 0.727 \\
\hline Being able to buy the exact quantity required & $33 \%$ & $43 \%$ & 1.123 & 0.289 \\
\hline Environmental protection & $30 \%$ & $43 \%$ & 1.123 & 0.289 \\
\hline Reduced price of the product & $26 \%$ & $7 \%$ & 3.646 & 0.056 \\
\hline Selling environment-friendly products & $4 \%$ & $13 \%$ & 1.434 & 0.231 \\
\hline Possibility of repeated use of own packaging & $13 \%$ & $20 \%$ & 0.373 & 0.541 \\
\hline
\end{tabular}

The analysis showed that the difference is statistically significant only in the advantage of selling quality products. The real customers perceive the selling of quality products to be an advantage much more often than those who do not do their shopping in zero-packaging stores. This advantage is cited by $33 \%$ of respondents shopping in zero-packaging stores, while respondents who do not do their shopping in zero-packaging stores cite this advantage in only $10 \%$ of cases.

\subsection{Disadvantages of Purchasing Consumer Chemicals in Zero-packaging Stores}

Regarding the disadvantages of purchasing consumer chemicals in zero-packaging stores, "insufficient expansion of stores" was most often mentioned (it was mentioned by more than a third of respondents). Other significant disadvantages are the "necessity to bring own containers" and the "higher price of the products sold". These three most significant disadvantages were mentioned by more than a quarter of respondents (see Figure 3). Some respondents also perceive "limited product selection", "necessity to plan the shopping", "time- 
consuming shopping", "hard-to-observe hygiene requirements" and "uncertainty of composition and quality of products" as disadvantages. The 'Other' category includes a number of disadvantages, such as shorter product shelf life, reluctance to change habits and more complex product handling.

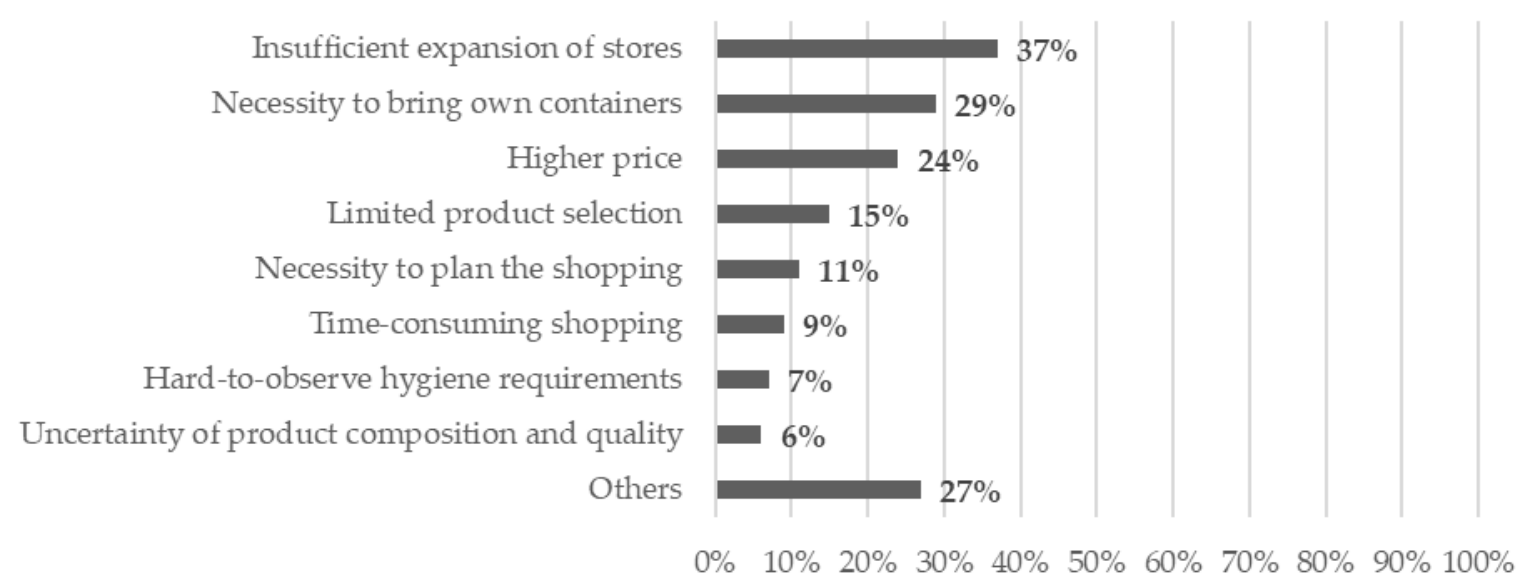

Figure 3. Disadvantages of shopping in zero-packaging stores

As with the advantages, it was interesting to examine to whether the opinion on the disadvantages of shopping in zero-packaging stores differs depending on whether the respondents actually do the shopping in zero-packaging stores (see Table 3).

Table 3. Differences in views on the disadvantages of shopping in zero-packaging stores depending on whether the purchases are actually made

\begin{tabular}{|c|c|c|c|c|}
\hline \multirow{2}{*}{ Disadvantage } & \multicolumn{2}{|c|}{ Percent of Customers } & \multicolumn{2}{c|}{ Chi-square Test } \\
\cline { 2 - 5 } & $\begin{array}{c}\text { Regular } \\
\text { Customers }\end{array}$ & $\begin{array}{c}\text { Customers of } \\
\text { zero-packaging } \\
\text { stores }\end{array}$ & Chi-square & P-value \\
\hline Insufficient expansion of stores & $33 \%$ & $47 \%$ & 1.177 & 0.278 \\
\hline Limited product selection & $9 \%$ & $30 \%$ & 5.976 & 0.015 \\
\hline Higher price & $13 \%$ & $50 \%$ & 13.912 & 0.000 \\
\hline Necessity to bring own containers & $31 \%$ & $23 \%$ & 0.333 & 0.564 \\
\hline Hard-to-observe hygiene requirements & $9 \%$ & $3 \%$ & 0.263 & 0.608 \\
\hline Time-consuming shopping & $9 \%$ & $10 \%$ & 0.000 & 1.000 \\
\hline Uncertainty of product composition and quality & $4 \%$ & $10 \%$ & 0.414 & 0.520 \\
\hline Necessity to plan the shopping & $9 \%$ & $17 \%$ & 0.700 & 0.403 \\
\hline
\end{tabular}

It was found that there is a statistically significant difference in two disadvantages, namely "limited product selection" and "higher price". Customers who purchase consumer chemicals in zero-packaging stores perceive these disadvantages to a much greater extent than those who do not do the shopping in these stores.

\section{Discussion}

The primary research found that a relatively small number of customers shop in zeropackaging stores. However, customers who prefer shopping in a zero-packaging store then recommend it to their friends. 
Regarding the identified advantages, the research is in line with previous research (Price, Waterhouse \& Co, 2015; Salkova \& Regnerova, 2020) in the advantages of waste elimination, reduction of environmental impact, quality of products sold and reuse of packaging. In addition, however, it revealed the advantage of "being able to buy the exact quantity required". This is a relatively often perceived advantage - it was cited by more than a third of all respondents and more than $40 \%$ of respondents who are also customers of zero-packaging stores. We consider this finding to be an addition to the advantages already revealed. It is likely that this advantage cannot be considered specific to the purchase of consumer chemicals in zero-packaging stores. The composition of the 'Other' category is interesting. The advantages cited therein indicate the individual benefits that customers get when shopping.

Research into the disadvantages of shopping in zero-packaging stores confirmed the conclusions come to by Beitzen-Heineke et al. (2017) and Salkova and Regnerova (2020), that the main disadvantages are the limited range of products, unavailability and a small number of stores and higher demands on the preparation of the shopping. In addition, it revealed other relatively important disadvantages, in particular the "necessity to bring your own containers", "higher price of products sold", "hard-to-observe hygiene requirements" and "uncertainty of the composition and quality of products". We consider the first two additional disadvantages revealed to be particularly important (cited by a quarter of respondents or more). Disadvantages "limited product selection" and "higher price" indicate the biggest differences in perception depending on whether the customers actually do the shopping in zero-packaging stores. Especially those who do consider them to be disadvantages. The 'Other' category indicates the existence of a number of problems that reduce the individual value to customers or small customer segments. At any rate, even in the case of disadvantages, the disadvantages revealed cannot be considered specific to the purchase of consumer chemicals. This leads us to the conclusion that the advantages and disadvantages of shopping in zero-packaging stores are perceived regardless of the products that are purchased. These are thus the advantages and disadvantages of the form of purchase.

\section{Conclusions}

The findings and conclusions of the research can be used to develop zero-packaging product sales. The advantages perceived by respondents shopping in zero-packaging stores are the reasons why the respondents shop in those stores. They make purchases here mainly for environmental reasons, but also partly for economic reasons (when they buy the exact quantity required). By contrast, perceived disadvantages are barriers to the wider expansion of this form of sale. Therefore, it is more important for companies to focus on the disadvantages perceived by customers who buy consumer chemicals in the traditional way (and do not use zero-packaging stores). Overcoming these barriers brings an opportunity to attract this segment of customers. This could be an opportunity especially for small and medium-sized businesses. However, it would also mean overcoming a number of internal corporate barriers. We assume these internal barriers to zero-packaging sales, but the professional literature does not yet offer their specific form. Therefore, we consider it 
appropriate to develop this research through follow-up research in companies (of various sizes) in order to identify the barriers preventing companies from implementing this form of sales. Research performed in companies not only of different sizes, but also of different industries (especially the food industry) would then make it possible not only to describe these barriers, but also to possible specifics, if any, according to the size of the company and individual industries.

Acknowledgments: This study was supported by a grant from the Fund for Bilateral Relations within the framework of the EEA and Norway Grants 2014-2021 (EHP-BFNU-OVNKM-3-134-01-2020).

\section{References}

Beitzen-Heineke, E. F., Balta-Ozkan, N., \& Reefke, H. (2017). The prospects of zero-packaging grocery stores to improve the social and environmental impacts of the food supply chain, Journal of Cleaner Production, 140(3), 1528-1541. https://doi.org/10.1016/j.jclepro.2016.09.227

Civancik-Uslu, D., Puig, R., Voigt, S., Walter, D., \& Fullana-i-Palmer P. (2019). Improving the production chain with LCA and eco-design: application to cosmetic packaging. Resources, Conservation E Recycling, 151, 104475.

Czech Statistical Office. (2020). Population composition by sex and age units as of 31.12. [Data set]. Retrieved February 20, 2020, from https://vdb.czso.cz/vdbvo2/faces/cs/index.jsf?page=vystup-objektparametry\&pvo=DEMD001\&sp $=$ A\&pvokc $=\& k a t a l o g=30845 \& z=T$

Dominic, C. A. S., Östlund, S., Buffington, J., \& Masoud, M. M. (2015). Towards a Conceptual Sustainable Packaging Development Model: A Corrugated Box Case Study, Packaging Technology and Science. An International Journal, 28(5), 397-413. https://doi.org/10.1002/PTS.2113

Dow. (1995-2020). We will deliver circular economy solutions. Dow. https://corporate.dow.com/en-us/science-andsustainability/plastic-waste/economy.html

Farooque, M., Zhang, A., Thürer, M., Qu, T., \& Huisingh, D. (2019). Circular supply chain management: A definition and structured literature review. Journal of Cleaner Production, 228, 882-900. https://doi.org/10.1016/j.jclepro.2019.04.303

Gustavo, J. U., Pereira, G. M., Bond, A. J., Viegas, C. V., \& Borchardt, M. (2018). Drivers, opportunities and barriers for a retailer in the pursuit of more sustainable packaging redesign. Journal of Cleaner Production, $187,18-28$.

Istas, D. Expansion of the local, organic and zero-packaging food concept in three contexts: zero-packaging grocery stores, conventional supermarkets, and ecostores. Master thesis. Maastricht University.

LEAD Innovation Blog. (2020). The packaging-free supermarket - trend or future? https://www.leadinnovation.com/english-blog/packaging-free-supermarket

Ma, X., Park, C., \& Moultrie, J. (2020). Factors for eliminating plastic in packaging: The European FMCG experts' view. Journal of Cleaner Production, 256, 120492. https://doi.org/10.1016/j.jclepro.2020.120492

Meherishi, L., Narayana, S. A., \& Ranjani K. S. (2019). Sustainable packaging for supply chain management in the circular economy: A review. Journal of Cleaner Production, 237, 117582. https://doi.org/10.1016/j.jclepro.2019.07.057

Price, Waterhouse \& Co (2015). Verpackungsfreie Lebensmittel - Nische oder Trend? https://www.pwc.de/de/handel-und-konsumguter/assets/pwc-verpackungsfreie-lebensmittel.pdf

Salkova, D., \& Regnerova, O. (2020). Methods of eliminating waste from food packaging as a globalization tool. In T. Kliestik (Ed.), The 19th International Scientific Conference Globalization and its Socio-Economic Consequences 2019 - Sustainability in the Global-Knowledge Economy (04025). https://doi.org/10.1051/shsconf/20207404025

Vörös, F. (2019). Plasty: Situace v Evropě je neradostná. Průmyslová ekologie. https://www.prumyslovaekologie.cz/info/plasty-situace-v-evrope-je-neradostna 